Hence if a small proportion of the whole fluid is irrotational, it is clear that there may be a minimum energy, and therefore a stable configuration of motion with the whole of this in one of the wide parts of the canister; or the whole in the other; or any proportion in one and the rest in the other; or a small portion in the elliptic whirl in the connecting canal, and the rest divided in any proportion between the two wide parts of the canister.

\section{ON THE SPECTRA OF THE COMPOUNDS OF CARBON WITH HYDROGEN AND NITROGEN}

MESSRS. LIVEING AND DEWAR have made a long ing is a brief abstract ${ }^{1}$ by the authors :-

The first experiments were made with a De Meritens dynamoelectric machine, arranged for high tension, giving an alternating current capable of producing an arc between carbon poles in air of from 8 to ro millims. in length. The carbon poles used had been previously purified by prolonged heating in a current of chlorine.

The arc was taken in different gases inside a small glass globe about 60 millims. in diameter, blown in the middle of a tube. The two ends of the tube were closed with dry corks, through which were passed (I) the carbons inserted through two pieces of narrow glass tubing; (2) two other glass tubes through which currents of the gases experimented with were sent.

The arc taken in a globe of air gave a tolerably bright continuous spectrum, above which the green and blue hydrocarbon bands were seen, also the seven bands in the indigo (wave-lengths 4,600 to 4,502 , Watts) as in the flame of cyanogen, and much more brightly the six bands in the violet (wave-lengths 4,220 to 4,158 , Watts) and five ultra-violet.

Carbonic acid gas, hydrogen, nitrosen, chlorine, carbonic oxide, nitric oxide, and ammonia were then successively substituted for air in the globe, with the result that in carbonic acid, hydrogen, chlorine, and carbonic oxide, the above-mentioned bands in the indigo, violet, and ultra-violet died away, while in nitrogen, nitric oxide, and ammonia, they were always well seen.

These different gases were used in order to eliminate to a large extent the influence of electric conductivity on the character of the spectrum; and the green and blue hydrocarbon bands were seen, more or less, in all of them.

Next observations were made of the spcctra of flames of sundry compounds of carbon.

In the flame of cyanogen, prepared from well-dried mercury cyanide, passed over phosphoric anhydride inserted in the same tube, and burnt from a platintum jet fused into the end of the tube, the hydrocarbon bands were almost entirely absent, as Plïcker and Hittorf had found; only the brightest green band was seen, and that faintly. The indigo, violet, and ultra-violet bands, on the other hand, were well developed.

These three sets of bands in the indigo, violet, and ultra-violet are in the sequel referred to as the "cyanogen bands," though it is possible that they may be producible by other compounds of carbon with nitrogen.

The flame of hydrocyanic acid burning in air showed very mitch the same as that of cyanogen.

In the flame of a mixture of purified hydrogen and carbon disulphide no hydrocarbon bands at all could be detected.

Nor could they be detected in the flame of a mixture of carbonic oxide ard hydrogen burnt in air.

When a mixture of hydrogen or of carbonic oxide with carbon tetrachloride vapour was burnt, hydrocarbon bands made their appearance, but were weak.

On the other hand, chloroform, when mixed with hydrogen, gave, when burnt in air, the hydrocarbon bands very strongly.

On a review of the whole series of observations, certain points stand out plainly. In the first place, the indigo, violet, and ultra-violet bands, characteristic of the flame of cyanogen, are conspictous in the arc taken in an atmosphere of nitrogen, air, nitric oxide, or ammonia, and they disappear almost, if not quite, when the are is taken in a non-nitrogenous atmosphere of hydrogen, carbonic oxide, carbonic acid, or chlorine. These same bands are seen brightly in the flames of cyanogen and hydrocyanic acid, but are not seen in those of hydrocarbons, carbonic oxide, or carbon disulphide. The conclusion seems irresistible that they belong to cyanogen; and this conclusion

$$
{ }^{I} \text { For fuller details sce Proc. R.S., xxx. pp. I52, 49-4. }
$$

does not seem to be at all invalidated by the fact that they are seen weakly, or by flashes, in the arc or spark taken in gases supposed free from nitrogen by reason of the extreme difficulty of removing the last traces of air. They are never, in such a case, the principal or prominent part of the spectrum, and in a continuous experiment they are seen to fade out in proportion as the nitrogen is removed. This conclusion is strengthened by the observations that cyanogen (or hydrocyanic acid) is generated in the arc in atmospheric air in large quantity.

In the next place, the green and blue bands, characteristic of the hydrocarbon flame, seem to be always present in the arc, whatever the atmosphere. This is what we should expect if they be due, as Angström and Thalèn suppose, to acetylene; for the carbon electrodes always contain, even when they have been long heated in chlorine, a notable quantity of hydrogen. In the flames of carbon compounds they by no means always appear; indeed it is only in those of hydrocarbons or their derivatives that they are well seen. Carbonic oxide and carbon disulphide, even when mixed with hydrogen, do not show them; and if seen in the flames of cyanogen, hydrocyanic acid, and carbon tetrachloride mixed with hydrogen, they are faint, and do not form a principal or prominent part of the spectrum. This is all consistent with the supposition of Angstrom and Thalèn. The fact that the bands are not produced even in the presence of hydrogen, when it is not present in the flame in the form of a compound with carbon, is very significant ; for we know that acetylene is present, and can easily be extracted from the flame of any hydrocarbon, and that it is formed as a proximate pro. duct of decomposition of hydrocarbon by the electric discharge, but we have no evidence that it is producible as a product of direct combination of carbon with hydrogen at the comparatively low temperature of the flames described.

The hydrocarbon bands are best developed in the blowpipe flame, that is under conditions which appear, at first sight, unfavourable to the existence of acetylene in the flame. IIowever, by the use of a Deville's tube, acetylene may readily be withdrawn from the interior of such a flame, and from that part of it which shows the hydrocarbon bands most brightly.

The question as to whether these bands are due to carbon. itself or to a compound of carbon with hydrogen, has been somewhat simplified by the observations of Watts, Salet, and others on the spectrum of carbonic oxide. It can hardly be doubted now that that compound has its own spectrum quite distinct from the hydrocarbon flame spectrum. The mere presence of the latter spectrum feebly developed in the electric discharge in compounds of carbon supposed to contain no hydrogen, weighs very little against the series of observations which connect this spectrum directly with hydrocarbons.

In the next place, it appears conclusively from the experiments, that the development of violet bands of cyanogen, or the less refrangible hydrocarbon bands, is not a matter of temperature only. For the appearance of the hydrogen lines $\mathrm{C}$ and $\mathrm{F}$, observed by the authors in the arc taken in hydrogen, indicates a temperature far higher than that of any flame. Yet the violet bands are not seen in hydrogen at that temperature, while the green bands are well developed. The violet bands are, nevertheless, seen equally well at the different temperatures of the flame, arc, and spark, provided cyanogen be the compound under observation in the flame, and nitrogen and carbon are present together at the higher temperatures of the are and spark.

The accompanying diagram (Fig. I) shows approximately the relative position of the bands in that part of the spectrum of the flame of cyanogen fed with a jet of oxygen which is more refrangible than the Fraunhofer line F. Only those bands which are less refrangible than the solar line $L$ have been before described, but photographs show two shaded bands slightly less refrangible than the solar line $\mathrm{N}$ accompanied by a very broad diffuse band of less intensity on the more refrangible side of $\mathrm{N}$; also a strong shaded band, which appears to be absolutely coincident with the remarkable shaded band in the solar spectrum, which has been designated by the letter P; and near this, on the less refrangible side, a much fainter diffuse band, which also seems to coincide with a part of the solar spectrum sensibly less luminous than the parts on either side of it. This spectrum is remarkably persistent at all temperatures of the flame. Watts found that it did not disappear when the flame was cocled down as much as possible by diluting the cyanogen with carbonic acid; it retains its characters when the cyanogen is burnt in nitric oxidc. The flame in the last case must be one 
of the hottest known, from the large amount of heat evolved in the decomposition of cyanogen and nitric oxide, namely, 4I, 000 and 43,300 units respectively. There is in the case of cyanogen, as in the case of so many other substances, a difference in the relative intensities of the different parts of the spectrum of the flame at different temperatures, but no other change of character. In the upper part of the flame where much or all of the cyanogen is oxidised or decomposed the spectrum is continuous, but at the base of the flame where it is issuing from the nozzle the cyanogen bands are always seen both when the cyanogen is burning in oxygen and when it is burning in nitric oxide. This is what we should anticipate, provided intermediate, and not the final, compounds are the active sources of the banded spectrum.

Each of the five sets of bands shown in the diagram is attended on its more refrangible side by a series of rhythmical lines extending to a considerable distance, not shown in the diagram, but easily seen in the photographs.

Coal gas burning in oxygen gives no bands above that near $G$ within the range of the diagram, Fig. I; $\cdot$ but beyond this photographs show a spectrum of a character quite different from that at the less refrangible end, which the authors have traced to be due to water and described elsewhere (Proc. R. S., No. 205).

The authors then describe experiments with carbon tetra. chloride, conducted with great care and numerous repetitions because of the prominence given to an experiment with this compound by Mr. Lockyer in a recent "Note on the Spectrum of Carbon," and because their results in every case differ from those which he obtained.

The form of sparking tube employed was similar to that used by Salet. This was attached by thick rubber tubing to a straight glass tube of which one half, about 6 inches long, was filled with phosphoric anlhydride, and the other half with small fragments of soda-lime to prevent any chlorine from the decomposition of the tetrachloride by the spark from reaching the Sprengel pump. The tetrachloride used had been fractionated until it had a constant boiling point of $77^{\circ} \mathrm{C}$. Sufficient of it was introduced into the sparking tube to fill nearly one quarter of the bulb at the end, and the whole interior of the tube thoroughly wetted with it in order to facilitate the removal of the last traces of air.

When the tube containing the tetrachloride had been so far exhausted that little but condensible vapours were pumped out, the bulb was heated so as to fill the apparatus with vapour of tetrachloride, the pump still going, and this was repeated as long as any incondensible gas was extracted. Sparks were then passed through the tube for a short time, the pump still being kept going. After a short time it was unnecessary to keep the pump going, as all the chlorine produced by decomposition of the tetachloride was absorbed by the soda-lime. On now examining the spectrum, no trace of any of the cyanogen bands could be detected, either by the eye or by photography, however the spark might be varied. The violet lines of chlorine described by Salet were more or less visible, coming out brightly when a condenser was used. Several tubes were treated in this way, and many photographs taken, but always with the same result; no trace appeared of either the seven blue, the six violet, the five ultra-violet, or of the still more refrangible bands of the cyanogen flame. It is true that all the photographs showed three lines in the ultra-violet, but these do not at all closely resemble the cyanogen bands, they are not shaded like them. The least refrangible of the three is coincident with the middle maximum in the ultra-violet set of five bands, but the other two do not coincide with other of these maxima. When a condenser is used, these three lines come out with much greater intensity, and two other triplets appear on the more refrangible side, as well as other lines.

The general character of the violet part of the spectrum of the spark in carbon tetrachloride taken without a condenser, but not the exact position to scale of wave-lengths of all the lines, is shown in Fig. 2. Fig. 3 shows the brightest of the additional lines which come out with the use of a condenser. Photographs of sparks taken in hydrochloric acid showed a precisely similar group of ultra-violet lines, so that there is no doubt that the three lines which the photographs show near the place of the ultra-violet cyanogen bands are due to chlorine.

Repeated trials in which the arrangements were varied having shown that pure carbon chloride, if free from nitrogen, does not give any of the bands ascribed to compounds of carbon with nitrogen, the next step was to determine whether the addition of nitrogen would bring them out, and if so what quantity of nitrogen would make them visible. For this purpose the binding of the rubber tube connecting to the pump a sparking tube containing tetrachloride and found to give no cyanogen bands, was loosened, and, after letting in very little air, immediately closed again. On now passing the spark the six violet bands at once appeared, and the seven blue bands also were in a short time well seen.

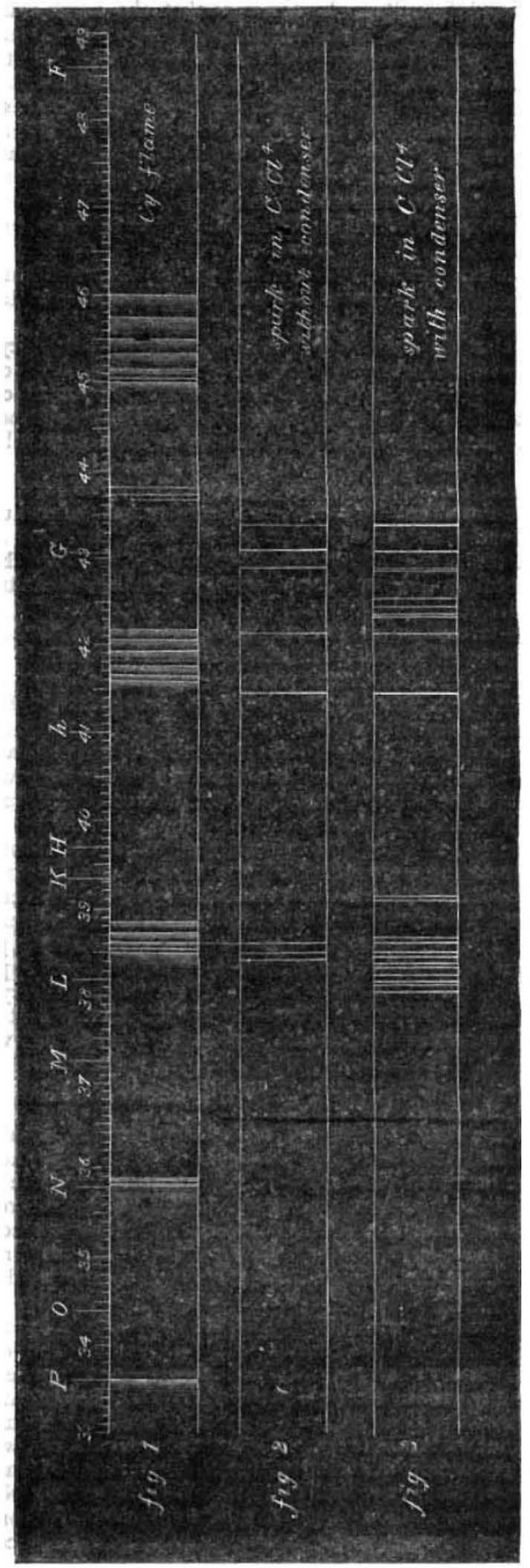

After trying some other experiments of a similar kind which indicated that a very small uantity of nitrogen was sufficient to develop the cyanogen bands in one of these tubes, a minute frag. ment of bichromate of ammonia, carefully weighed and wrapped in platinum foil, was introduced into the neck of one of the 
sparking tubes containing carbon tetrachloride, the tube connected to the Sprengel pump, and the air removed as before. On examination of the spark with the spectroscope no trace of any cyanogen band could be detected. A pinch-cock was now put on the rubber tube, and the bichromate was heated by a spirit lamp to decomposition (whereby it is resolved into nitrogen, water, and oxide of chromium). On now passing the spark the six violet bands were well seen. There was no change in the condition of the coil or rheotome, so that the spark was of the same character as it had been before when no cyanogen bands were visible, and the change in the spectrum cannot be attributed to any change in the spark. The weight of the bichromate was between 0005 and 0006 grm., and the nitrogen this would evolve would fill just about $\frac{1}{20}$ of a cubic centimetre at atmospheric pressure. The tube held 30 cub. centims., so that vapour of carbon tetrachloride when mixed with $\frac{1}{00}$ part of its volume of nitrogen, gives under the action of the electric spark the cyanogen bands distinctly. Other similar experiments confirmed this result.

Similar experiments with carbon bisulphide, benzol, and wellpurified naphthaline, gave like results when care was taken to remove air completely.

As Watts laid much stress on the occurrence of the cyanogen bands in the spectrum of the spark taken in carbonic oxide at atmospheric pressure (though they do not appear in carbonic oxide at reduced pressures), as a proof that these bands were due to carbon only, the authors made a series of careful experiments with carbonic oxide at atmospheric pressures.

In the first experiments with this substance the gas was made by the action of sulphuric acid on dried formiate of sodium, and it was found that the cyanogen bands disappeared as air was expelled from the apparatus, reappearing brightly when air, not exceeding $\frac{1}{400}$ of the whole gas in the apparatus, was admitted.

Carbonic oxide was next generated by heating, in a tube of hard glass in an ordinary combustion furnace, a mixture of pure and dry potassium oxalate with one quarter of its weight of quicklime, the mixture having been previously heated for some time so as to expel traces of ammonia. The tube was connected with a Sprengel pump, and the air exhausted before heating the oxalate. The distant end of the tube with the oxalate was then heated, and the whole apparatus filled with carbonic oxide; it was then again exhausted with the pump, refilled by heating more oxalate, and the gas allowed to stream out through the pump for some time. The heat was then lowered, sparks were passed, and the spectrum observed. No trace whatever of the cyanogen bands could be detected, however the spark might be varied. The pump was now set going again, and the pressure of the gas reduced to one inch of mercury, while the spectrum was observed from time to time. Still no trace of the cyanogen bands could be detected. More of the oxalate was next heated, and the observations repeated again and again, always with the same result. The conclusion was that carbonic oxide, if quite free from nitrogen, does not give, at the atmospheric or any less pressure, the cyanogen bands.

From Dr. Watts's account of his experiments, it appeared that he had used carbonic oxide prepared by the action of sulphuric acid on ferrocyanide, and it was probable that it might have been contaminated with nitrogen, or with nitrogenous compounds, from the ferrocyanide. The authors accordingly repeated their experiments with carbonic oxide so prepared, and found that the cyanogen bands were then always distinctly seen.

They have also repeated Ångström and Thalén's experiments with the spark between carbon poles in nitrogen and carbonic acid gas. They observed that in nitrogen the cyanogen bands were plainly visible through a great range of variations of the character of the spark; even the use of a condenser of moderate size did not diminish them. Photographs were taken with and without the use of the condenser, and these showed the violet and ultra-violet cyanogen bands, including those near $\mathrm{N}$ and $\mathrm{P}$. The nitrogen was then swept out by a current of carbonic acid gas, and on now passing the spark the cyanogen bands could no longer be detected, and photographs taken as before showed no trace of any of them.

Other experiments showed the sensitiveness of the spectro. scopic tests for compounds of carbon with nitrogen, and that all traces of water can hardly be removed from apparatus and reagents which do not admit of being heated red hot.

The first point the authors had before them in these investi- gations is whether the groups of shaded bands seen in the more refrangible part of the spectrum of a cyanogen flame are due to the vapour of carbon uncombined, or, as they conclude, to a compound of carbon with nitrogen.

Now the evidence that carbon uncombined can take the state of vapour at the temperature of the electric arc is at present very imperfect. Carbon shows at such temperatures only incipient fusion, if so much as that, and that carbon uncombined should be vaporised at the far lower temperature of the flame of cyanogen is so incredible an hypothesis that it ought not to be accepted if the phenomena admit of any other probable explanation. On the other hand it has been shown that cyanogen or hydrocyanic acid is generated in large quantity in the electric arc taken in nitrogen, and Berthelot has shown that hydrocyanic acid is produced by the spark discharge in a mixture of acetylene and nitrogen, so that in the cases in which these bands shine out with the greatest brilliance, namely, the arc in nitrogen and the cyanogen flame, we know that nitrocarbon compounds are present. Further, the authors have shown that these bands fade and disappear in proportion as nitrogen is removed from the arc. Angström and Thalèn had previously shown the same thing with regard to the spark discharge between carbon electrodes; and the conclusion to which they have come would probably have commanded universal assent if it had not been for the fact that these bands had been seen in circumstances where nitrogen was supposed to be absent; but where, in reality, the difficulty of completely eliminating nitrogen, and the extreme sensibility of the spectroscopic test, had been inadequately apprehended.

To clear up the question from this point of view, the experiments last described have been made, and they appear to the authors quite conclusive. Were the evidence less conclusive than it is, it would still be as rash and as illogical to conclude from the appearance of the cyanogen bands in a case where nitrogen was presumed, not proved, to be absent, that they were not due to a compound of carbon with nitrogen, as it would be to deny that the well-known yellow lines were due to sodium, because they had been seen in cases where sodium was supposed to be absent. The argument of the authors is an induction from a very long series of observations which lead up to one conclusion, and hardly admit of any other explanation. But Mr. Lockyer attempts to explain the disappearance of the bands when nitrogen is absent by the statement "that the tension of the current used now brings one set of flutings into prominence, and now another." This is no new observation. It is well known that variations in the discharge produce variations in the relative intensities of different parts of a spectrum. Certain lines of magnesium, cadmium, zinc, and other metals, very brilliant in the spark, are not seen, or are barely seen, at all in the arc. His remark might be applied to the spectra of compounds as well as to those of elements. Variation in the discharge accounts very well for some of the variations of intensity in the bands if they be due to a compound of carbon with nitrogen; it will not, however, account for the fact that the bands, or those of them which have the greatest emissive power, and are best developed by the particular current used, come out on the addition of a minute quantity of nitrogen, when there is every reason to think that no variation of the current occurs.

Much the same may be said with regard to the changes of the spectrum produced by changes of temperature. We cannot infer from any of these changes that the spectrum is not due to a compound. The bands in question are singularly persistent through a great range of temperatures, from the temperature of a cyanogen flame cooled by admixture with carbonic acid gas, as related by Watts (Phil. Mag, 1869, p. 258), to that of the spark of an induction coil with condenser.

But again, Mr. Lockyer attempts to get over the difficulties of his case by the supposition that "the sets of carbon flutings represent different molecular groupings of carbon, in addition to that or those which give us the line spectrum."

Now, until independent evidence that carbon can exist at all in the state of vapour uncombined at the temperature of a cyanogen flame can be adduced, and further independent evidence of the existence of different groupings in such vapour, the hypothesis here enunciated is a gratuitous one, so long as any other hypothesis for which independent evidence can be adduced, as is true of the existence of nitrocarbon compounds in the flame, arc, and spark, will sufficiently explain the facts.

The authors have not expressed any opinion whether or no the cyanogen bands are visible in the solar spectrum. The observa- 
tion above recorded that there is in the spectrum of cyanogen a strong shaded band coincident with the very characteristic dark shaded band $P$, strengthens materially the evidence in favour of the existence of these bands in the solar spectrum; the more so as the series of lines at $\mathrm{P}$ has far more of the distinctive character of the cyanogen spectrum than any other series in the ultraviolet part of the solar spectrum.

However that may be, they contend against the hypothesis that if present the bands can be due to any vapour of carbon uncombined in the upper cooler region of the chromosphere. One object of their investigations has been to determine the permanence of compounds of non-metallic elements and the sensitiveness of the spectroscopic test in regard to them. It appeared probable that if such compounds existed in the solar atmosphere their presence would be most distinctly revealed in the more refrangible part of the spectrum, and it seems sufficiently clear that the presence of nitrogen in the solar atmosphere may be recognised through cyanogen when free nitrogen might escape detection.

\section{UNIVERSITY AND EDUCATIONAL INTELLIGENCE}

OxFord.-The Millard Scholarship in Natural Science lately founded at Trinity College has been awarded for the first time. The successful candidate is $\mathrm{Mr}$. R. Bodey, from the Mining School, Bristol, and from the Royal School of Mines.

At Exeter College the Natural Science Scholarship has been awarded to Mr. B. Spencer, from King's College, London.

According to the report of the Delegates for unattached students, the number of students not attached to any college or hall has increased by twenty during the past year. Seventy unattached students have become members of colleges or halls during the year.

CAMBRIDGe.-The University of Cambridge Commissioners have apparently proposed their final arrangements as regards the University. There are many modifications from the original scheme in the direction of giving more freedom to the University, and on the whole in favour of scientific objects. A general financial board is to manage all University property and expenditure, and to control especially the college contributions. The rating of the colleges for University purposes is modified in the direction of increased fairness. The common University Fund derived from the colleges is to provide for all classes of Uni. versity teachers, for the salaries of demonstrators, superintendents, and curators, for the erection, maintenance, and furniture of muscums, laboratories, libraries, lecture-rooms; and in addition grants of money may be made from it for special work in the way of research, and for investigations in any branch of learning or science connected with the studies of the University. The amount of proments for buildings, and their maintenance, furniture, and apparatus, is not to exveed onc-third of the income of the fund in any one year.

Practically speaking, there may be available in each year to the end of $1884,2,000 l$. a year for these latter purposes and $4,000 l$. for investigators and teachers, and the college payments will rise definitely to $30,000 l$., of which $10,000 l$. may be used for the purposes of buildings, and $20,000 l$. for teachers of all kinds.

It is no longer sought to force particular professors on particular colleges ; the college may, if it prefers, pay the income of a Professorial Fellowship to the common fund. There are to be twenty-nine Professorial Fellowships, not assignable to particular professors, but distributed among the colleges.

The stipends of the Professors, payable by the University, are to have 200l. deducted from them if the Professor holds a Professorial Fellowship or a Headship. The 'stipends of Professors as now proposed are not so unequal as in the first proposed statutes. The payments (subject to the above-mentioned deduction) to the Regius Professor of Physic would be 7ool., Professor of Chemistry and the Cavendish Professor of Physics $850 l$. each, Physiology $800 \%$., Pathology 8ool., Botany, Zoology, and Woodwardian of Geology 70ol. each, Anatomy $600 /$ The new Professorships are to be for (I) Physiology, (2) Pathology, (3) Mental Philosophy and Logic. The first two professors are not to undertake the private practice of medicine and surgery. When these shall have been established, the University may establish any other professorships it pleases, or has funds for.

The proposals for readerships are also to be remarkably modi. fied ; the minimum number of readers is now twenty. The sub jects are to be within the control of the University; the readers are to be appointed as soon as funds can be provided conveniently from the common University Fund or from other sources. Readerships may be suppressed or created, according to the needs of study. The stipend is to be $400 l$. The readers are to be appointed by grace of the Senate on the recommendation of the General Board of Studies now to be created; but in each case the special Board of Studies with which the readership is connected must concur in the appointment, or it will lapse to the Council of the Senate.

University Lecturers (the next grade of teachers) may be college lecturers who throw open their lectures to the University, or they may be other persons approved by the Boards of Studies.

The payment to these lecturers from the University must be not less than $50 l$. The University may also appoint lecturers on subjects not immediately connected with any special Board of Studies, for shorter or longer terms. The separation of the Board of Studies in Physics and Chemistry from that of Biology and Geology is maintained. The constitution of the General Board of Studies is carefully and completely defined; but it is to do such work as the Senate commits to it, and in future a general University budget is to be prepared and submitted to the Senate.

The Cambridge Museums and Lecture Rooms Syndicate find the increase of annual grant from the University from $1,500 l$. to $2,000 \%$. a year inadequate, owing especially to new outlay on new departments. They now have a balance of $82 \mathrm{r} l$, against them ; and they ask for an additional $1,000 l$. per annum at once, feeling quite unable otherwise to maintain the museums in moderate efficiency with strict economy.

\section{SCIENTIFIC SERIALS}

Fournal of the Franklin Institute, September.-Experiments on the compression of air by the direct action of water, by J. P. Frizell. -Experiments on the strength of yellow pine, by R. H. Thurston - - The absolute economy of electric lighting, by $\mathrm{R}$. Briggs.-Note on the artificial production of diamonds by the processes of Despretz, by E. J. Houston.

October.-Motion of viscous fluids, by T. Craig. - The steam yacht Anthracite and the Perkins system of high pressure steam, by G. Deane.-Coal gas engineering, by R. Briggs.-Holman's new illustration of cell-formation, by J. M. Child.-Joseph Henry, by A. M, Mayer.

American Naturalist, October.-S. A. Forbes, the food of the darters.-J. C. Russell, on the former extent of the triassic formation of the Atlantic slates.-C. C. Abbott, notes on stone implements found in New Jersey.-S. Lockwood, some noteworthy birds.-W. K. Higley, on the microscopical crystals contained in plants.-The editor's table.-Biology at the Ameri can Association at Buston. Recent literature.-General notes, -Scientific news.

Reale Istituto Lombardo di Scienze e Lettere. Rendiconti, vol. xiii. fasc. xvi., July 29.-On a particular univocal correspondence between elements of space with three dimensions, by F. Aschieri.-Case of unproductivity of corn, by G. Cantoni.On the thermal and luminous phenomena manifested by the Leyden jar at the moment of its discharge, by E. Villari.Transformation of aspartic acid into fumaric acid, by G. Korner and A. Menozzi,-First case of repeated peritoneal transfusion, with new and happy : uccess, in an oligocitemic insane person, by C. Golgi and A. Raggi.--On the infirmity of Torquato Tasso, by A. Corradi.-Meteorological summary of the year 1879 , from meteorological observations at the Brera Observatory, by $\mathrm{P}$. Frisiani.

Rivistct Scientifico-Industriale, September 15.-Further experiments with a Crookes' tube, by A. Righi.-Histology of the skin of Teleostean fishes, by A. Batelli.

\section{SOCIETIES AND ACADEMIES \\ LONDON}

Entomological Society, October 6.-H. T. Stainton, F.R.S., vice-president, in the chair.-Sir Arthur Scott of Birmingham and Mr. F. E. Robinson were elected as ordinary Members. - Mr. McLachlan stated that last year he had exhibited 